\title{
Synthesis and Characterization of Silver Hydrosols in the Presence of Carboxyalkylated Amine Complexones
}

\author{
G. P. Shevchenko ${ }^{a, *}$, V. A. Zhuravkov ${ }^{a}$, E. V. Tret'yak ${ }^{a}$, \\ A. G. Novikov ${ }^{b}$, and O. V. Korolik ${ }^{b}$ \\ ${ }^{a}$ Research Institute of Physicochemical Problems, Belorussian State University, Minsk, 220030 Belarus Republic \\ ${ }^{b}$ Department of Physical Electronics and Nanotechnologies, Belorussian State University, Minsk, 220030 Belarus Republic \\ *e-mail: gvidonashevchenko@gmail.com \\ Received September 1, 2016
}

\begin{abstract}
The specifics of formation of silver nanoparticles in aqueous solution in the presence of carboxyalkylated amine complexones (NTA and DTPA) have been studied for the first time. Sols with these ligands are found to be formed in alkali solutions at $\mathrm{pH} \geq 10.0$ and $80^{\circ} \mathrm{C}$. Their optical spectra and the particle sizes and morphologies are determined by synthesis conditions: $\mathrm{pH}$, the ratio $\mathrm{Ag}^{+} / \mathrm{L}$, and the order of mixing components. A scheme has been suggested for silver nanoparticle formation in the presence of NTA and DTPA, consistent with the experimental results. The efficacy of the prepared silver sols in SERS measurements is shown.
\end{abstract}

DOI: $10.1134 / \mathrm{S} 0036023618010163$

The methods usually used to prepare metal nanoparticles, in particular, silver and gold precious metals in the form of sols, involve the reduction of metal ions in aqueous solutions in the presence of macromolecular compounds and surfactants, which serve as stabilizers $[1,2]$. The polymer film that is formed on the surfaces of nanoparticles when such stabilizers are used significantly affects their spectral characteristics. This reduces the effectiveness of use of nanoparticles prepared by these methods in highly sensitive fluorescence spectroscopy and Raman spectroscopy, and in solving biosensoric problems.

The synthesis of silver sols in the presence of $\mathrm{Na}_{2}$ EDTA (disodium salt of ethylenediaminetetraacetic acid) is briefly mentioned in the literature, these sols to be used for detecting the Raman signal from single molecules adsorbed on their surfaces [3, 4]. The formation of silver nanoparticles in $\mathrm{Na}_{2}$ EDTA solutions was studied in detail, the reaction scheme was determined, and the morphological features of the particles were studied as dependent on synthesis parameters [5, 6]. Here, we report on our studies into silver sol formation in the presence of other carboxyalkylated amine complexones, namely, nitrilotriacetic acid (NTA) and diethylenetriaminepentaacetic acid (DTPA), without reducing agents and without polymeric stabilizers. No relevant data have been found in the literature.

\section{EXPERIMENTAL}

Solutions of $0.01 \mathrm{M} \mathrm{AgNO}_{3}, 0.075 \mathrm{M} \mathrm{NaOH}, 0.006 \mathrm{M}$ NTA, and 0.008 M DTPA were used to prepare silver sols. The silver sol preparation procedure was as described in our previous paper [6], where various orders of mixing components were used. In variant 1 , NTA (DTPA) and $\mathrm{NaOH}$ solutions were mixed to obtain the working value of $\mathrm{pH}$; in variant 2 , NTA (DTPA) and $\mathrm{AgNO}_{3}$ solutions were mixed. In both cases, after being mixed the solutions were thermostated at $80^{\circ} \mathrm{C}$; a silver nitrate solution (in variant 1 ) or $\mathrm{NaOH}$ solution (in variant 2) was added under vigorous stirring, and then the solution was exposed at this temperature for $20 \mathrm{~min}$. Silver concentration in all sols was $5 \times 10^{-4} \mathrm{~mol} / \mathrm{L}$.

Absorption spectra were recorded on a Cary 500 double-beam spectrophotometer in the wavelength range 200-1200 $\mathrm{nm}$. Measurements were carried out in a 1-cm silica glass cell with in fourfold diluted sols. The morphology and grain sizes of sols were determined by transmission electron microscopy (TEM) using an EM-125K instrument. The efficacy of Raman signal amplification was studied by recording Raman spectra on a Nanofinder High End (Lotis TII) unit with 473-nm laser excitation.

\section{RESULTS AND DISCUSSION Sol Formation in the Presence of DTPA}

Figures 1 and 2 show the absorption spectra of silver sols prepared in the presence of DTPA as a func- 
(a)

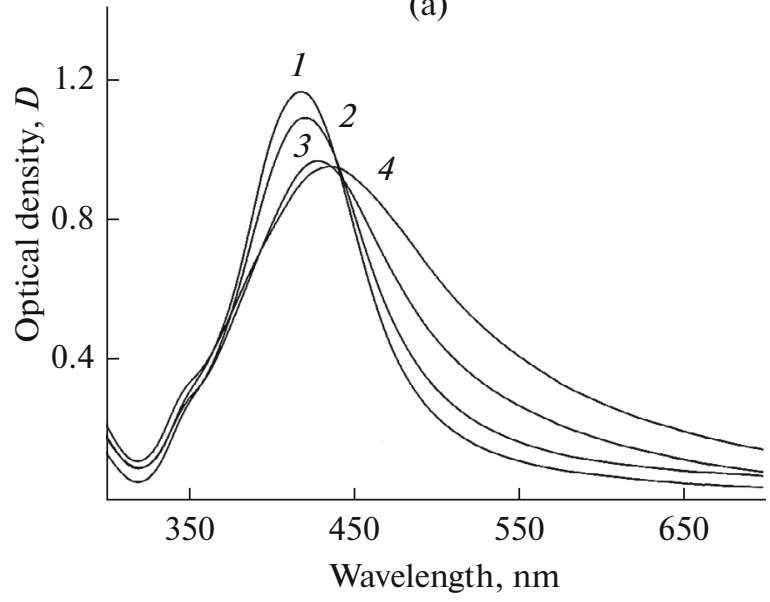

(b)

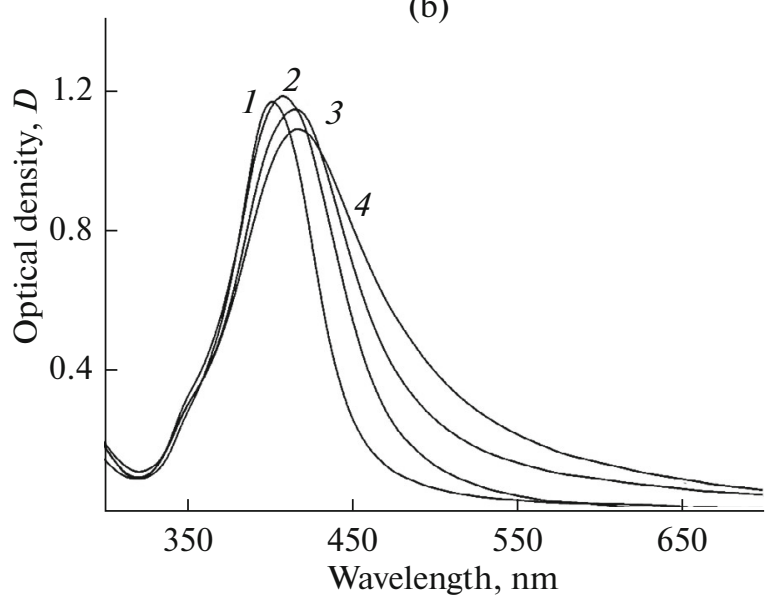

Fig. 1. Optical spectra as a function of the ratio $\mathrm{Ag}^{+}: \mathrm{L}(\mathrm{pH} 11.9)$ for silver sols prepared under various synthesis conditions in (a) variant 1 and (b) variant $2:$ (1) $1: 0.75$, (2) $1: 0.5$, (3) $1: 0.33$, and (4) $1: 0.2$.

tion of sol synthesis conditions, namely, the order of mixing components, the ratio $\mathrm{Ag}^{+} / \mathrm{L}$, and $\mathrm{pH}$. The gels were formed in alkali media $(\mathrm{pH}>10)$ at elevated temperature $\left(80^{\circ} \mathrm{C}\right)$ and $\mathrm{Ag}^{+} / \mathrm{L}>1$, independently of the order in which the components were mixed. Noteworthy, when $\mathrm{Ag}^{+}: \mathrm{L}=1: 1$, sol formation virtually does not occur. The maximal optical density of the sol is attained for $\mathrm{Ag}^{+}: \mathrm{L}=1: 0.7$ and $\mathrm{pH} 11.6-12.0$ in both variants, the evolution of the spectra of the sols as a function of $\mathrm{Ag}^{+} / \mathrm{L}$ being, however, different (Fig. 1). In variant 1 , this evolution is insignificant. When $\mathrm{Ag}^{+}$: $\mathrm{L}=1: 0.7$, the sol has $D_{\max } \sim 1.2$ and $\lambda_{\max }=420 \mathrm{~nm}$. As the amount of the ligand decreases further relative to $\mathrm{Ag}^{+}$, the maximal optical density of the sol starts to decline with the simultaneous red shift of $\lambda_{\max }$ from 420 to $450 \mathrm{~nm}$ and a considerable broadening of the long-wavelength component of the absorption band

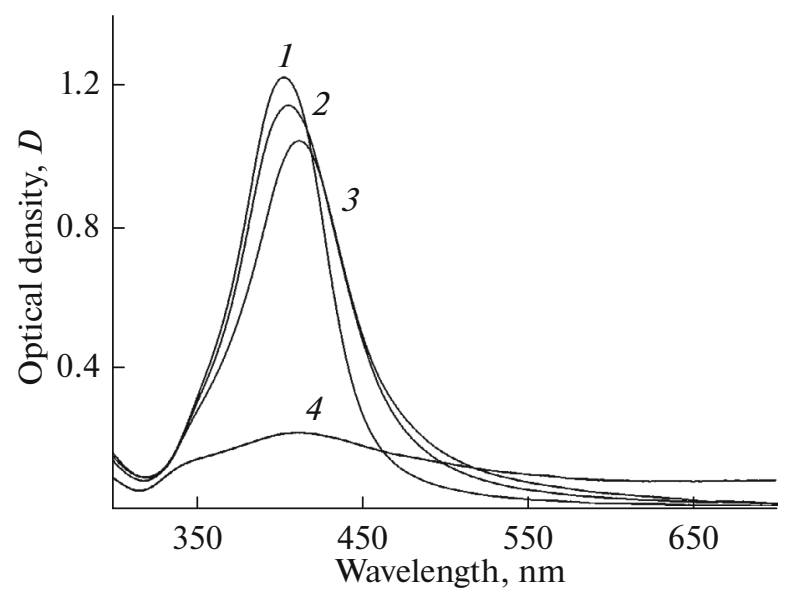

Fig. 2. Optical spectra of silver sols as a function of $\mathrm{pH}$ in the reaction medium $\left(\mathrm{Ag}^{+}: \mathrm{L}=1: 0.5\right):(1) 12.0,(2) 11.6$ (3) 11 , and (4) 10.6.
(Fig. 1a; spectra 3, 4). In variant 2, the optical spectra of the sols are little dependent on the ratio $\mathrm{Ag}^{+} / \mathrm{L}$ in the range under study, while holding the tendency to broadening, reducing the optical density of the sol, and shifting $\lambda_{\max }$ to the red in response to decreasing ligand amount (Fig. 1b)

As the ligand amount decreases, the stability of the sols deteriorates markedly: for $\mathrm{Ag}^{+}: \mathrm{L}=1: 0.5$, the sol is stable for at least one week, and when $\mathrm{Ag}^{+}: \mathrm{L}=1$ : 0.2 , for $\sim 12 \mathrm{~h}$. At higher ligand amounts $\left(\mathrm{Ag}^{+} / \mathrm{L} \leq 1\right)$, sols are not formed even when the synthesis time is $60 \mathrm{~min}$.

Sol formation in the presence of DTPA depends on reaction $\mathrm{pH}$ to a considerable extent. Regardless of the order in which the components were mixed, within $10<\mathrm{pH} \leq 12.0$ the optical density of the sol decreases, the optical spectrum is broadened, and $\lambda_{\max }$ experiences an insignificant shift to the red (Fig. 2). When $\mathrm{pH}<10$, sols are not formed.

TEM studies show that, in the presence of DTPA, silver particle morphology and particle size in sols only insignificantly depend on the synthesis variant (Figs. 3a, $3 b$ ). Particle sizes are within $20-30 \mathrm{~nm}$; almost all particles have rounded shapes.

As the ligand amount decreases, particle sizes increase to $50-70 \mathrm{~nm}$, their dispersion rises, and they acquire a more distinct edging (Fig. 3c). These results agree with optical spectroscopy, which shows broadening of the spectra and the red shift of $\lambda_{\text {max }}$ (Fig. 1).

\section{Sol Formation in the Presence of NTA}

Silver sol formation in the presence of NTA has some specific features compared to DTPA. Variant 1 at $\mathrm{pH} 12.0$ yields a weakly colored sol, whose optical spectrum has low optical density $D_{\max } \sim 0.5$ (the optical spectrum was measured without dilution) and fea- 
(a)
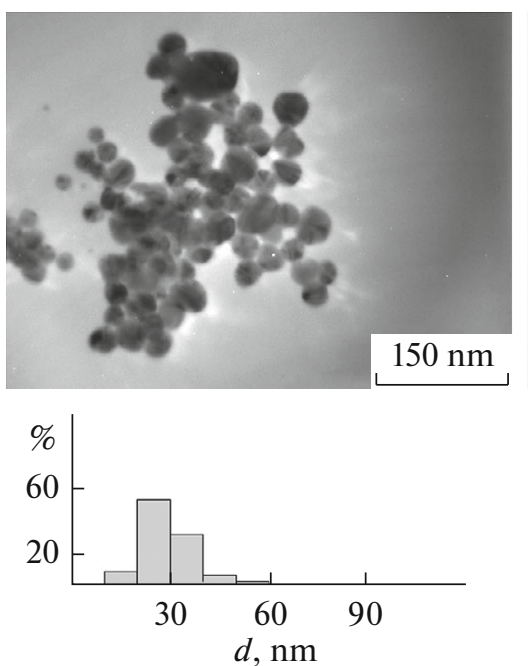

(b)
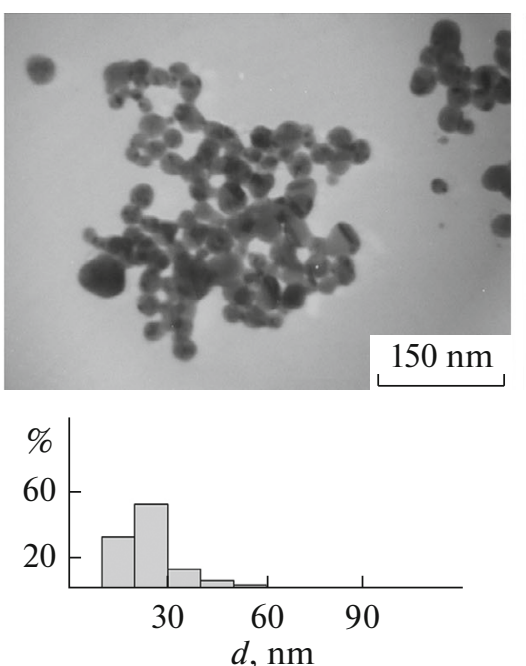

(c)
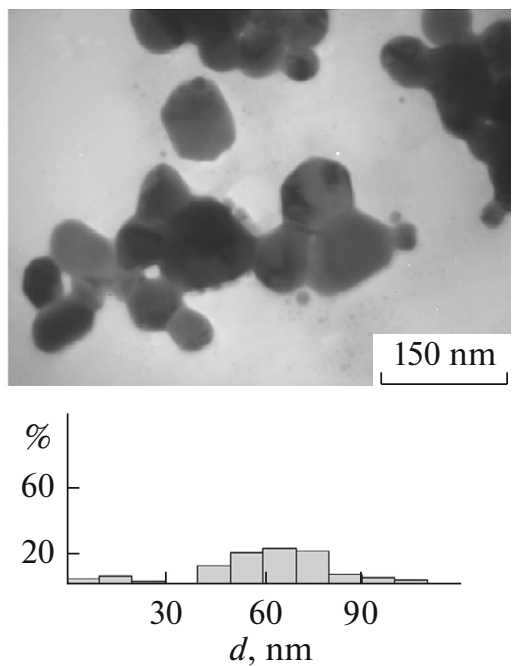

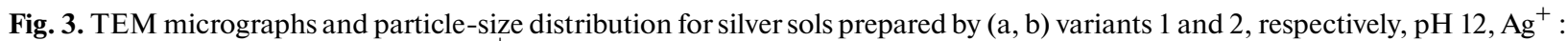
$\mathrm{L}=1: 0.5$; and (c) variant $1, \mathrm{pH} 12, \mathrm{Ag}^{+}: \mathrm{L}=1: 0.25$.
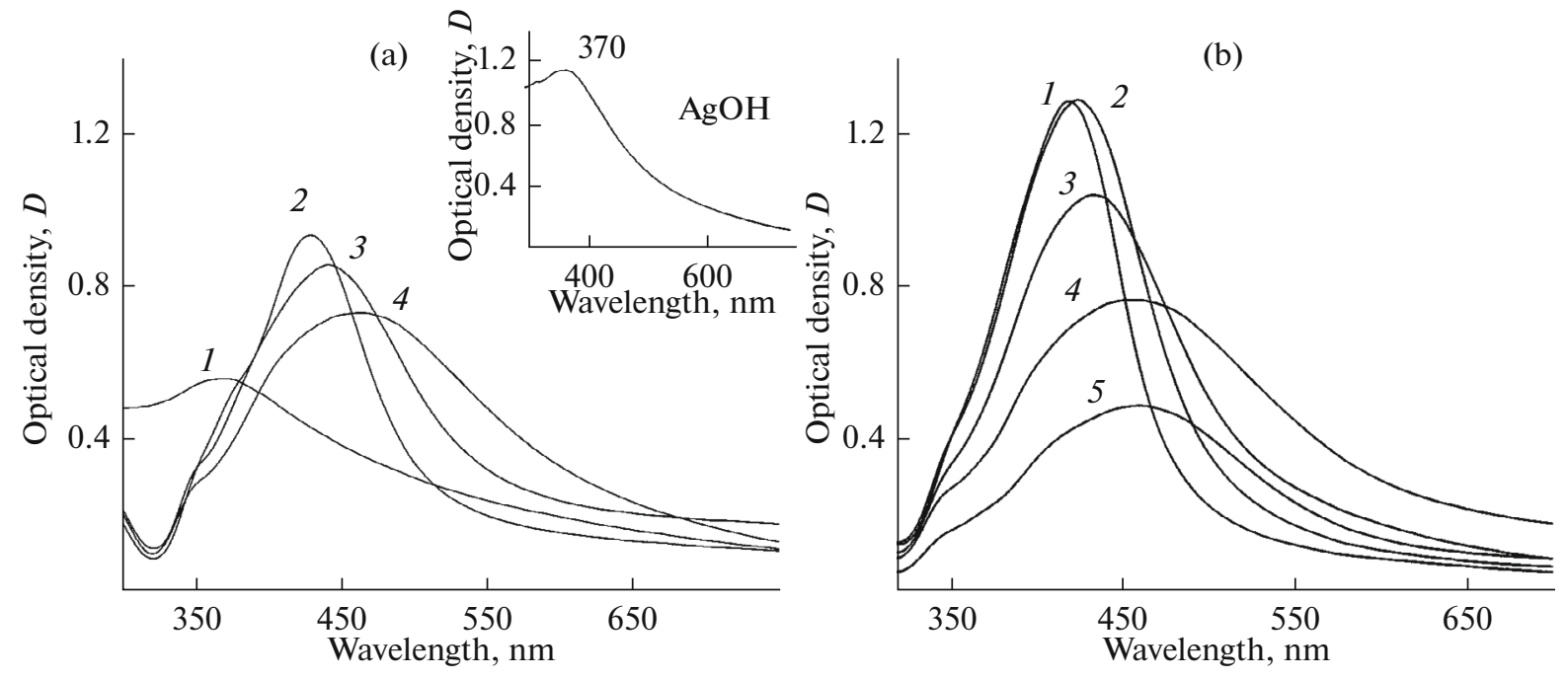

Fig. 4. Optical spectra of silver sols as a function of $\mathrm{pH}$ in the reaction medium $\left(\mathrm{Ag}^{+}: \mathrm{L}=1: 1\right)$ : (a) variant $1:$ (1) 12.0 , (2) 11.7 , (3) 11.4, and (4) 11.1; and (b) variant 2: (1) 12.0, (2) 11.6, (3) 11.0, (4) 10.6, and (5) 10.4.

tures a broad peak at 362-375 nm (Fig. 4a, spectrum 1). This spectrum was found to be identical to the spectrum $\mathrm{Ag}_{2} \mathrm{O}\left(\mathrm{Ag}^{+}, \mathrm{OH}^{-}\right)$sol, which is formed upon addition of $\mathrm{NaOH}$ to a silver nitrate solution without NTA up to $\mathrm{pH} 12.0$ (Fig. $4 \mathrm{a}$, spectrum $\mathrm{Ag}_{2} \mathrm{O}$, inset). When $\mathrm{pH}$ slightly decreases to the range within 11.911.7, the produced sols have high optical densities $D_{\max } \sim 1.0$ at $\lambda_{\max }=425 \mathrm{~nm}$ (Fig. 4a, spectrum 2).

At pH of 11.1 (Fig. 4a; spectra 3, 4), the spectra are broadened, the optical density of the sol becomes lower, and $\lambda_{\max }$ experiences a shift to $462 \mathrm{~nm}$. At $\mathrm{pH} \leq$ 11.0, sol formation is noticeably slowed down; at $\mathrm{pH} \leq$ 10.0, sols are not formed. In variant 2 (Fig. 4b), sol formation occurs over a wider $\mathrm{pH}$ range, in particular, at $\mathrm{pH} 12.0$, unlike in variant 1 . The effect of $\mathrm{pH}$ on the optical spectra of the sols holds the same trends: the spectra are broadened as $\mathrm{pH}$ decreases, the optical density is reduced, and $\lambda_{\text {max }}$ shifts to the red (Fig. $4 b$ ).

Another specific feature of silver sol formation in the presence of NTA is the possibility to obtain sols with considerable amounts of the ligand. Sol formation (in variant 2) was found to proceed until $\mathrm{Ag}^{+}: \mathrm{L}=$ $1: 10$ (Fig. 5a), while the $\lambda_{\max }$ position remained almost unchanged remaining in the region of $\sim 425 \mathrm{~nm}, D_{\max }$ decreased noticeably with increasing ligand amount. We found that this was due to an appreciable alteration 
(a)

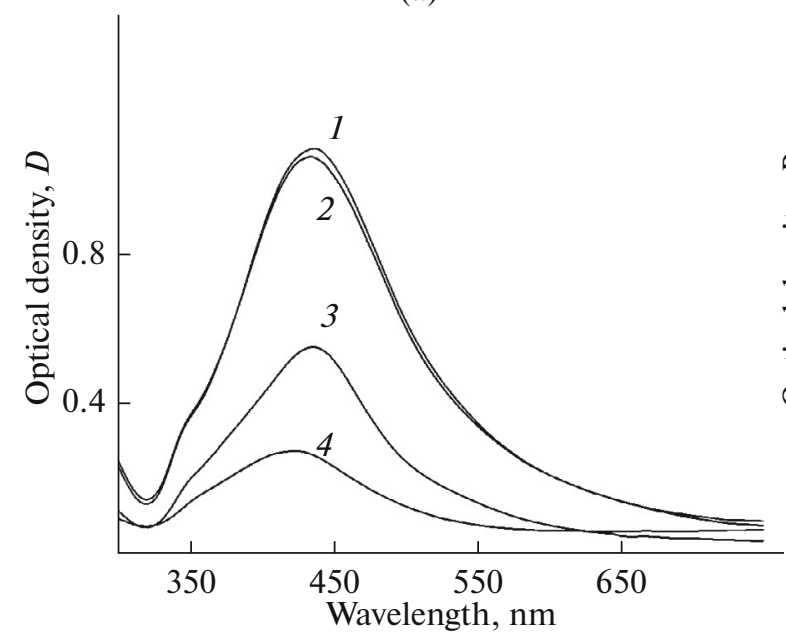

(b)

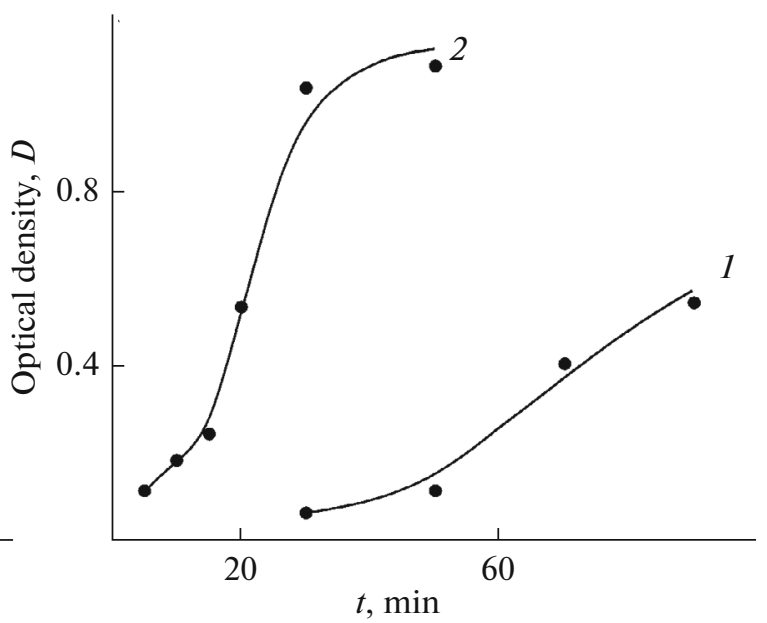

Fig. 5. (a) Optical spectra of silver sols (variant $2, \mathrm{pH} 11.9$, synthesis time $20 \mathrm{~min}$ ) as a function of the ratio $\mathrm{Ag}^{+}: \mathrm{L}(1) 1: 1$, (2) $1: 2$, (3) $1: 4$, and (4) $1: 10$. (b) Optical density of sols (at $\lambda_{\text {max }}$ ) versus synthesis time $\left(\mathrm{Ag}^{+}: \mathrm{L}=1: 4, \mathrm{pH} 11.9\right):(1)$ variant 1 and (2) variant 2 .

(a)
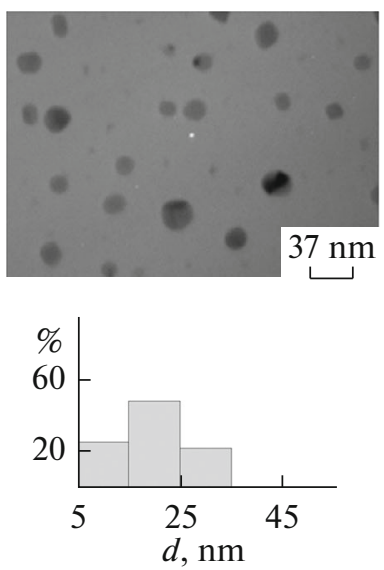

(b)
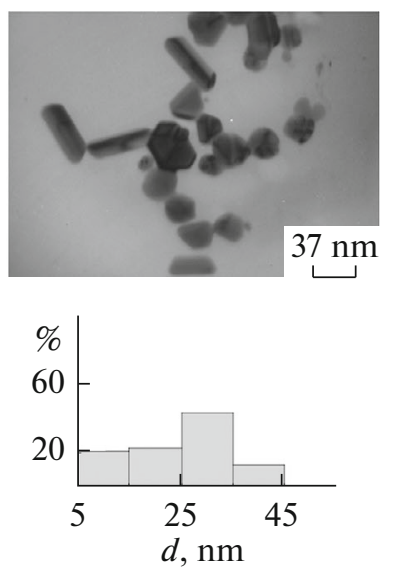

(c)
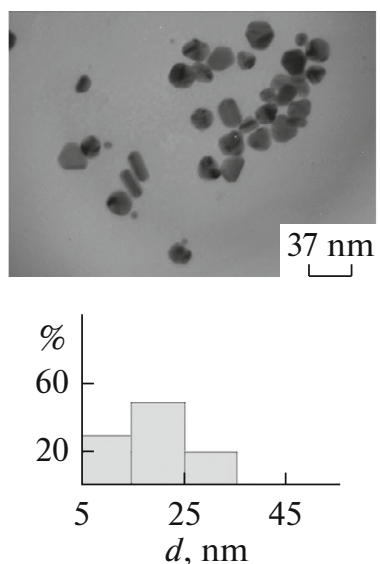

(d)
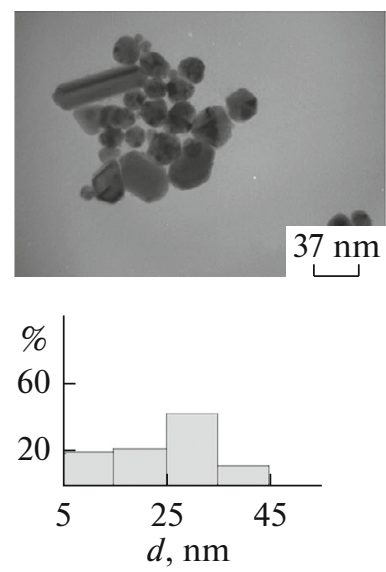

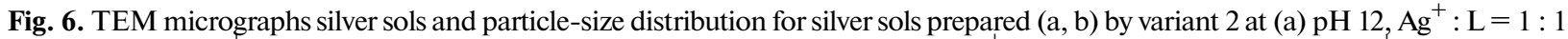
and (b) $\mathrm{pH} 12, \mathrm{Ag}^{+}: \mathrm{L}=1: 4$ and (c, d) prepared by variant 1 at (c) $\mathrm{pH} 11.8, \mathrm{Ag}^{+}: \mathrm{L}=1: 1$ and (d) $\mathrm{pH} 11.4, \mathrm{Ag}^{+}: \mathrm{L}=1: 1$.

of sol formation kinetics (Fig. 5b). While $20 \mathrm{~min}$ are needed to acquire $D_{\max }$ when $\mathrm{Ag}^{+}: \mathrm{L}=1: 1, \sim 60 \mathrm{~min}$ are needed for this when $\mathrm{Ag}^{+}: \mathrm{L}=1: 4$ (Fig. 5b, curve 2). In variant 1 , sol formation also occurs with greater NTA amounts, but far more slowly (Fig. 5b, curve 1). Noteworthy, sols are formed with smaller NTA amounts, but their stability is low (less than $12 \mathrm{~h}$ ). When $\mathrm{Ag}^{+}: \mathrm{L}=1: 0.1$, sols are not formed: precipitation occurs.

TEM data (Fig. 6) agree with the observed evolution of the optical spectra of silver sols prepared under various synthesis conditions, primarily associated with changes in particle size, particle dispersion, and morphology. Decreasing reaction $\mathrm{pH}$ lead to increasing silver particle sizes and greater sol dispersions (Figs. 6c, 6d); accordingly, its optical spectrum is broadened and the peak shifts to longer wavelengths (Fig. 4; curves 2, 4).

A change in ligand amount also gives rise to considerable changes in particle sizes and their morphology in sols (Figs. 6a, 6b): along with rounded particles, rodlike species appear. It was determined experimentally that their formation is observed predominantly in the synthesis according to variant 2 and $\mathrm{Ag}^{+} / \mathrm{L}<1$.

In order to study the efficacy of silver sols prepared in the presence of NTA and DTPA in SERS measurements, we measured their Raman spectra depending on the synthesis conditions (Fig. 7).

For comparison, Fig. 7 shows Raman spectra of NTA and DTPA solutions. In the absence of silver nanoparticles, these complexones are not identified in 


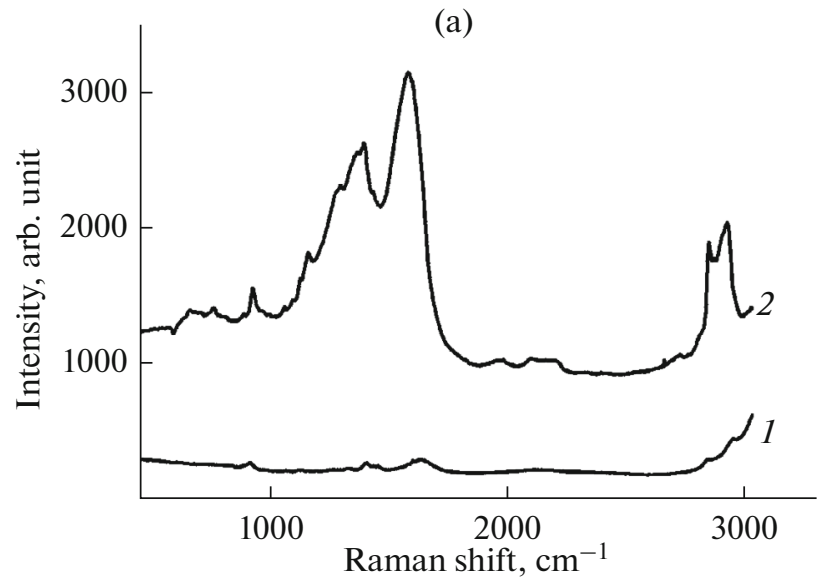

(b)

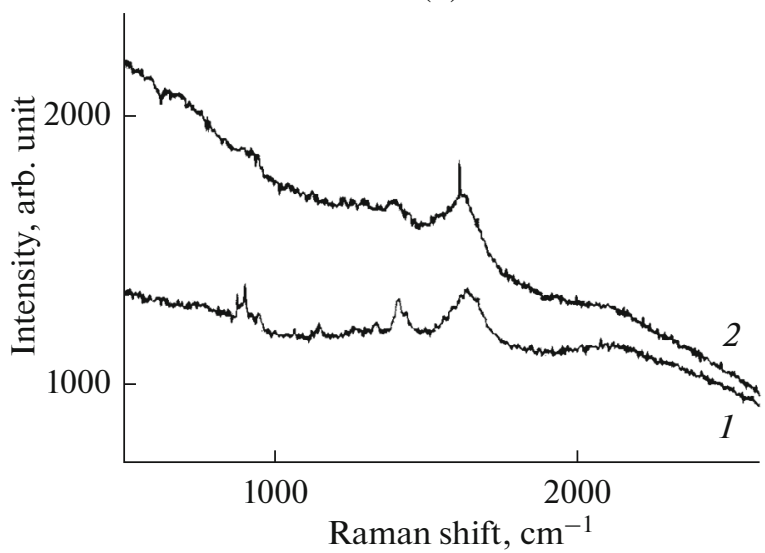

Fig. 7. Raman spectra measured with 473-nm laser excitation for silver sols prepared in the presence of DTPA ((a) curve 2 , $\mathrm{Ag}^{+}: \mathrm{L}=1: 0.5$, variant $\left.1, \mathrm{pH} 11.9\right)$ and NTA ((b) curve $2, \mathrm{Ag}^{+}: \mathrm{L}=1: 1$, variant $\left.1, \mathrm{pH} 11.9\right)$. Curves 1 correspond to the Raman spectra of 0.1 M solutions of (a) DPTA (a) and (b) NTA.

Raman spectra due to their low concentrations, so Figs. 7a and $7 \mathrm{~b}$ (curves 1) show the spectra of complexonate solutions whose concentrations are some two orders of magnitude higher than in silver sols.

The Raman spectra of the sols feature almost all bands characteristic of NTA and DTPA [7, 8], the strongest being the peaks at 929 and $1400 \mathrm{~cm}^{-1}$ arising from $\mathrm{C}-\mathrm{C}$ bonds and symmetrical $\mathrm{COO}$ bond, respectively [9-11]. The peak position at $1593 \mathrm{~cm}^{-1}$ can be due to the vibrations of a water molecule and the asymmetric vibrations of $\mathrm{COO}$ bond. Comprising the intensities of the major Raman bands, we found that Raman amplification for the DTPA-containing sols is $10^{8}$, being $10^{6}$ in the case of NTA.

From the above data it follows that silver sols in the presence of NTA and DTPA, as well as those prepared with $\mathrm{Na}_{2}$ EDTA [6], are formed only in alkali media $(10 \leq \mathrm{pH} \leq 12.0)$ and under heating. Their optical spectra and the sizes and morphology of silver particles are determined, to an appreciable extent, by synthesis conditions: the order of mixing components, $\mathrm{pH}$, and ratio $\mathrm{Ag}^{+} / \mathrm{L}$. The observed effect is due to different silver complexes (protonated $\mathrm{MH}_{x} \mathrm{~L}$, neutral ML, or their mixtures), having different $K_{\text {st }}$, being formed in solution in the presence of complexonates depending on the above-listed synthesis parameters.

In view of the fact that increasing ligand amounts considerably slow down the process (in case of NTA) or even completely stop it (in case of DTPA), we may conclude that carboxyalkylated amines do not manifest their reductive abilities under the conditions of our experiments.

The formation scheme of silver nanoparticles can be suggested as involving $\mathrm{AgOH}$ formation and its degradation under the conditions of our experiments to yield $\mathrm{Ag}_{2} \mathrm{O}$, which is thermally unstable and decomposes by
$2 \mathrm{Ag}^{+}+2 \mathrm{OH}^{-} \rightarrow \mathrm{Ag}_{2} \mathrm{O}+\mathrm{H}_{2} \mathrm{O} \rightarrow 2 \mathrm{Ag}+1 / 2 \mathrm{O}_{2}+\mathrm{H}_{2} \mathrm{O}$

For this scheme to operate, the condition should be fulfilled that $\mathrm{IP}_{\mathrm{AgOH}}>\mathrm{SP}_{\mathrm{AgOH}}$, which is determined by the value of $K_{\text {st }}$ of the formed silver complexes. Under the conditions of our experiments, at $\mathrm{pH}<10.0$ and $c_{\mathrm{Ag}+}=5 \times 10^{-4} \mathrm{~mol} / \mathrm{L}$ silver hydroxide is not precipitated and silver sols are not formed, which is another piece of evidence for our suggested scheme.

The role of complexones is to form silver complexonates, whose compositions and, accordingly, $K_{\text {st }}$ can be tuned by synthesis parameters, namely, $\mathrm{pH}, \mathrm{Ag}^{+} / \mathrm{L}$, and the order of mixing components, to produce silver sols having various optical parameters, particle sizes and morphologies. The thus-formed silver complexes serve to supply $\mathrm{Ag}^{+}$ions into solution, and the complexone itself is a stabilizer for nanoparticles.

In order to prove our suggested scheme of sol formation in the presence of complexones with the literature $K_{\text {st }}$ values of $\mathrm{Ag}: \mathrm{L}=1: 1$ silver complexes of the ligands under consideration $\left(K_{\mathrm{st}}\right.$ is 5.4 for the NTA complex, 7.3 for $\mathrm{Na}_{2}$ EDTA, and 8.7 for DTPA [12, 13]), we calculated the ion product (IP) of $\mathrm{Ag}^{+}$and $\mathrm{OH}^{-}$as a function of the molar ratio $\mathrm{Ag}^{+} / \mathrm{L}$ for $c_{\mathrm{NaOH}}=7.1 \times 10^{-3} \mathrm{~mol} / \mathrm{L}$ (Fig. 8).

From Fig. 8, it flows that $\mathrm{IP}_{\mathrm{Ag}^{+}, \mathrm{OH}^{-}}$values are virtually comparable for $\mathrm{Na}_{2}$ EDTA and DTPA at $\mathrm{Ag}^{+}: \mathrm{L}=$ $1: 1$, although for DTPA compared to $\mathrm{Na}_{2}$ EDTA, $\mathrm{IP}_{\mathrm{Ag}^{+}, \mathrm{OH}^{-}}$is slightly lower than $\mathrm{SP}_{\mathrm{Ag}^{+}, \mathrm{OH}^{-}}=1.6 \times 10^{-8}$ [14]; that is, silver sols should be formed at this ratio, in agreement with the experiment. In case of NTA at $\mathrm{Ag}^{+}: \mathrm{L}=1: 1, \mathrm{IP}_{\mathrm{Ag}^{+}, \mathrm{OH}^{-}}$is 20 times $\mathrm{SP}_{\mathrm{Ag}^{+}, \mathrm{OH}^{-}}$, which implies that silver sols can be formed at higher NTA amounts. Indeed, in the presence of NTA sols are formed at $\mathrm{Ag}^{+}: \mathrm{L}=1: 10$. The observed slow rates of 


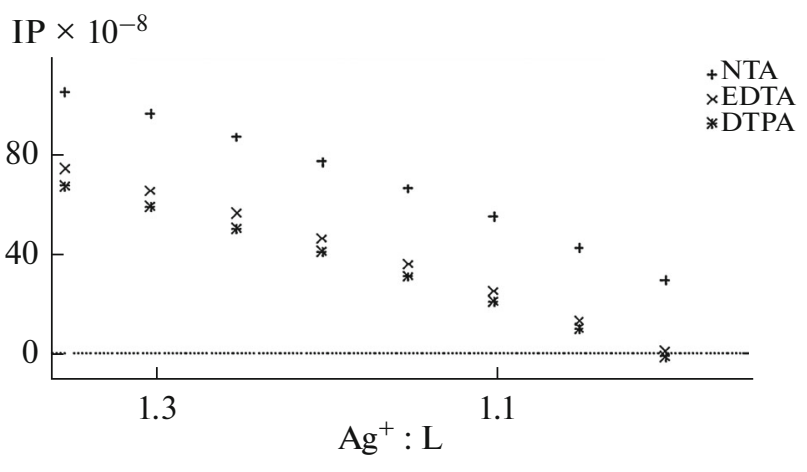

Fig. 8. $\mathrm{IP}_{\mathrm{Ag}^{+}, \mathrm{OH}^{-}}$versus molar ratio $\mathrm{Ag}^{+}: \mathrm{L}$ at $c_{\mathrm{NaOH}}=$ $7.1 \times 10^{-3} \mathrm{M}(\mathrm{pH} 11.8)$.

sol formation at the same $\mathrm{pH}$ (Fig. 5b) regardless of synthesis conditions (variants 1 and 2 ) can be associated with the changed compositions of complexes and their increased $K_{\mathrm{st}}$.

The unusual course of the process in the presence of NTA at $\mathrm{pH} 12$ and $\mathrm{Ag}^{+}: \mathrm{L}=1: 1$ in variant 1 , namely, the formation of $\mathrm{Ag}_{2} \mathrm{O}$ sol, can be explained as follows. At $\mathrm{pH} 12$, NTA is known to ionize completely to yield sodium complexonate [15]. Upon addition of $\mathrm{Ag}^{+}$to this solution (variant 1 ), a silver complex is likely to have no enough time to form, and $\mathrm{Ag}_{2} \mathrm{O}$ is immediately formed in alkali solution, not precipitating due to the low silver concentration $\left(5 \times 10^{-4} \mathrm{~mol} / \mathrm{L}\right)$ but rather forming a sol. At $\mathrm{pH}<12$ protonated complexes with sodium ions are formed; they are less stable and are likely to decompose completely. In this case, silver complexes with NTA are formed upon addition of $\mathrm{Ag}^{+}$ (variant 1), and these complexes provide for the formation of silver nanoparticles under these conditions, in accordance with the suggested scheme. The noticeable distinction of the course of synthesis of sols in the presence of NTA (as distinct from DTPA) is most likely to arise from the low geometric sizes of NTA and its low denticity compared to DTPA $[15,16]$.

\section{CONCLUSIONS}

This paper is published to report the results of our studies into the specifics of preparation of silver sols in the presence of NTA and DTPA without reducing agents and without polymeric stabilizers. Silver sols with these complexones, as well as those formed in the presence of $\mathrm{Na}_{2}$ EDTA [6], are formed only in alkali solutions ( $\mathrm{pH}$ within $10.0-12.0)$ and under heating $\left(80^{\circ} \mathrm{C}\right)$. Unlike sols comprising DTPA, sols with NTA are formed over a wide range of $\mathrm{Ag}^{+} / \mathrm{L}$ values and comprise rodlike particles along with rounded species. A scheme has been suggested for silver nanoparticle formation in the presence of NTA and DTPA, which have a dual function of the ligand for silver ions and the stabilizer for silver nanoparticles. The feasibility to prepare silver sols with various properties using carboxyalkylated amine complexones implies their potential for use in SERS measurements. The silver sols prepared in the presence of DTPA are most attractive for use in SERS measurements due to their particles having more uniform sizes and shapes compared to NTA-containing sols.

\section{REFERENCES}

1. A. V. Loginov, V. V. Gorbunova, and T. V. Boitsova, Zh. Obshch. Khim. 67, 189 (1997).

2. T. Sigimoto, Adv. Colloid Interface Sci. 28, 65 (1987).

3. S. M. Heard, F. Grieser, C. G. Barraclough, and J. V. Sanders, J. Colloid Interface Sci. 93, 545 (1983).

4. A. Fabrikanos, K. A. Athanassiou, and K. H. Lieser, Z. Naturforsch. B 18, 612 (1963).

5. E. V. Tret'yak and T. V. Koval'chuk, Rusnanotech, 376 (2008).

6. G. P. Shevchenko, V. A. Zhuravkov, E. V. Tretyak, et al., Colloids Surf. A 446 (5), 65 (2014).

7. K. Nakamoto, Infrared and Raman Spectra of Inorganic and Coordination Compounds, Sixth ed. (Wiley, 2009).

8. K. Krishnan and R. A. Plane, J. Am. Chem. Soc. 90, 3195 (1968).

9. D. A. Guzonas, G. F. Atkinson, D. E. Irish, and W. A. Adams, J. Electroanal. Chem. 150, 457 (1983).

10. H. Wetzel, B. Pettinger, and U. Wenning, Chem. Phys. Lett. 75, 173 (1980).

11. B. E. Douglas and D. J. Radanovich, Coord. Chem. Rev. 128, 139 (1993).

12. A. E. Martell and R. M. Smith, Critical Stability Constants (Plenum, London/New York, 1974).

13. R. Pribil, Analytical Applications of EDTA and Related Compounds (Pergamon, Oxford, 1972).

14. Yu. Yu. Lur'e, Handbook of Analytical Chemistry (Khimiya, Moscow, 1979) [in Russian].

15. N. M. Dyatlova, V. Ya. Temkina, and K. I. Popov, The Complexones and Metal Complexonates (Khimiya, Moscow, 1988) [in Russian].

16. T. Moeller and L. C. Thompson, J. Inorg. Nucl. Chem. 24, 499 (1962).

Translated by $O$. Fedorova 